\title{
Maternal Kronik Hepatit B Virüs Enfeksiyonu Gebelik ve Fetal Riskleri Artırıyor Mu?
}

\author{
Does Maternal Chronic Hepatitis B Virus Infection \\ Increase Pregnancy and Fetal Risks? \\ Handan Alay ${ }^{1}$, Melek Şahiner ${ }^{2}$, Emine Parlak ${ }^{1}$ \\ ${ }^{1}$ Atatürk Üniversitesi Tip Fakültesi, Enfeksiyon Hastalıkları ve Klinik Mikrobiyoloji A.D, Erzurum \\ ${ }^{2}$ Nenehatun Kadın Doğum Hastanesi, Enfeksiyon Kontrol Birimi, Erzurum \\ ORCİD \\ Handan Alay https://orcid.org/0000-0002-4406-014X \\ Melek Şahiner https://orcid.org/0000-0002-1124-708X \\ Emine Parlak https://orcid.org/0000-0001-8912-6360 \\ Yazışma Adresi / Correspondence: \\ Dr. Handan Alay \\ Atatürk Üniversitesi, Tip Fakültesi, Enfeksiyon Hastalıkları ve Klinik Mikrobiyoloji A.D \\ E-mail: alayhandan@gmail.com
}

Geliş Tarihi / Received : 18-10-2019

Kabul Tarihi / Accepted : 05-11-2019

Yayın Tarihi / Online Published: 27-12-2019

Alay H., Șahiner M., Parlak E., Maternal Kronik Hepatit B Virüs Enfeksiyonu Gebelik ve Fetal Riskleri Artırıyor Mu?, J Biotechnol and Strategic Health Res. 2019;3(2):208-212 DOİ:10.34084/bshr.634572

\footnotetext{
Öz

Amaç Dünyada 400 milyondan fazla kişi Hepatit B virüs (HBV)’üi ile enfektedir. Hepatit B virüs (HBV) enfeksiyonun gebeler üzerindeki etkisi açık değildir. Gebelikte kronik HBV varlığının gestasyonel diyabet, antepartum hemoraji, erken doğum tehdidi, yenidoğan sarılığı, düşük doğum ağırlığı gibi maternal ve fetal riskleri artırdığı belirtilmektedir. Bu çalıșmanın amacı HBV'nin gebelik ve fetal riskler üzerine etkilerini araștırmaktır.

Gereç ve 2014-2017 ylları arasında hastanemizde canlı doğum yapan HBV ile enfekte 301 gebe ve bebeği vaka grubu; aynı ylllarda rastgele seçilen, hastanemizde canlı doğum yapan Yöntemler HBV ile enfekte olmayan gebeler ve bebekleri kontrol grubu olarak çalısmamıza dahil edildi. Retrospektif olarak hasta dosyalarından doğum şekli, abortus, preeklampsi, gestasyonel diyabet, antepartum hemoraji, fetal distres, gebelik haftası, doğum ağırlı̆̆ı, intrauterin gelișme geriliği (IUGR) gibi maternal ve fetal sonuçları analiz edildi.

Bulgular Çalışmaya dahil edilen 301 HBsAg pozitif gebe kadının 189 (\%62,8)'unun doğum şekli normal vajinal doğum, 4 (\%1,3)'ü diyabetes mellitus, 2 (\%0,7)'i preeklampsi, 82 $(\% 27,2)$ 'inde abortus öyküsü ve 5 (\%1,7)'inde plesanta dekolmanı mevcuttu. HBsAg pozitif ve HBSAg negatif hastalar arasında istatiksel olarak anlamlı fark tespit edilmedi $(\mathrm{p}>0,05)$. HBsAg $(+)$ annenin $6(\% 2)$ bebeğinde IUGR ve $12(\% 40)$ 'inda fetal distres vardı. HBsAg $(+)$ anne bebeklerinde fetal distres varlı̆̆ açısından anlamlı fark vardı (p:0,036).

Sonuç Yapılmış bir çok çalışmada HBV enfeksiyonunun maternal ve fetal komplikasyonları artırdığı gösterilmiș olmasına rağmen çalışmamızda yalnızca fetal distres riskini anlamlı olarak bulduk. Çalışmamızda dikkat çeken nokta HBV varlı̆̆ının hekimin doğum şekline karar vermesini etkilemediğini gördük.

Anahtar gebelik, fetal, risk, hepatit B enfeksiyonu

Kelimeler

Abstract

Objective More than 400 million people worldwide are infected with the hepatitis B virus (HBV). The effect of HBV infection on pregnant women is unclear. The presence of chronic HBV in pregnancy has been reported to increase such maternal and fetal risks as gestational diabetes, antepartum hemorrhage, prematurity, neonatal jaundice, and low birth weight. The purpose of this study was to investigate the effects of $\mathrm{HBV}$ on pregnancy and fetal risks.

Materials and Three hundred and one pregnant women infected with HBV and giving live birth in our hospital in 2014-2017, and their babies, were enrolled as the case group, while randomly selected preg. Methods nant women giving live birth in our hospital and not infected with $\mathrm{HBV}$, and their babies, were included as the control group. Maternal and fetal outcomes such as type of delivery, miscarriage, re-eclampsia, gestational diabetes, antepartum hemorrhage, fetal distress, gestational weeks, and intrauterine growth restriction (IUGR) were analyzed retrospectively from patients' records.

Results Delivery was by the normal vaginal route in 189 (62.8\%) of the $301 \mathrm{HBsAg-positive} \mathrm{women} \mathrm{in} \mathrm{the} \mathrm{study,} \mathrm{while} \mathrm{diabetes} \mathrm{was} \mathrm{present} \mathrm{in} 4$ (1.3\%), pre-eclampsia in 2 (0.7\%), a history of miscarriage in $82(27.2 \%)$, and placental detachment in $5(1.7 \%)$. No statistically significant difference was determined between these and the HBsAg-negative women ( $p>0.05)$. IUGR was present in the babies of $6(2 \%)$ of HBs $A g(+)$ mothers, and fetal distress in $12(40 \%)$. The presence of fetal distress was significantly higher in the babies of HBsAg(+) mothers (p:0.036).

Conclusion Although several studies have shown that HBV infection increases maternal and fetal risks, only the risk of fetal distress was significant in our study. The noteworthy finding of our study is that the presence of $H B V$ did not affect the physician's decision regarding type of delivery.

Keywords pregnancy, fetal, risk, hepatitis B infection
} 


\section{GIIRIŞ}

Dünyada 400 milyondan fazla kişi Hepatit B virüs (HBV)'ü ile enfektedir ${ }^{1,2}$. Avrupa'da gebe kadınlardaki HBV sıklığı \%1 olarak tahmin edilmektedir ${ }^{3}$. Gebeliğin kronik HBV'ye etkisi ve kronik HBV enfeksiyonunun gebelik üzerindeki etkisi çok iyi bilinmemektedir ${ }^{4}$. Gebelikte kronik HBV varlı̆̆ının maternal ve perinatal komplikasyonları artırdığıını gösteren çalışmalar mevcut olmasına karşın, bazı çalışmalarda HBV varlığının perinatal komplikasyonlar açısından HBV'si olmayan gebelere göre farklılık olmadığı bildirilmektedir ${ }^{5,6,7}$. Bu çalışmada gebelerde HBV enfeksiyonunun maternal ve fetal riskler üzerine etkisini araştırmayı amaçladık.

\section{Materyal ve Metod}

Çalışmamıza 2014-2017 yılları arasında hastanemizde doğum yapan, yaşları 26-35yaş arasında olan $301 \mathrm{HBsAg}$ pozitif gebe ve bebeklerini hasta grubu olarak aldık. Aynı yllarda rastgele seçilen, hastanemizde canlı doğum yapan, HBV ile enfekte olmayan gebeler ve bebeklerini ise kontrol grubu olarak çalışmamıza dahil ettik. Hastaların doğum şekli, abortus, preeklampsi, gestasyonel diyabetes mellitus (GDM), antepartum hemoraji bilgileri ile bebeklerin fetal distres varlığı, gebelik haftası, doğum ağırlığ ve intrauterin gelişme geriliği (IUGR) sonuçlarını hastane otomasyon sistemi ve hasta dosyalarından retrospektif olarak taradık. Veri girişi ve analizi SPSS 20 paket program kullanılarak yapıldı. $\mathrm{P}<0.05$ olan değerler istatistiksel olarak anlamlı kabul edildi.

\section{Bulgular}

HBsAg pozitif gebelerin 189 (\%62.8)'u normal vajinal doğum, 112 (\%37.2)'si sezaryen doğum idi. HBsAg negatif gebelerin 195 (\%64.8)'i vajinal doğum, 106 (\%35.2)'si sezaryen ile doğum idi. HBsAg pozitif ve negatif gebelerde normal vajinal doğum ile sezaryen doğum arasinda istatiksel olarak anlamlı sonuç yoktu ( $\mathrm{p}>0.05)$. HBsAg pozitif gebelerin 82 (\%27.2)'inde abortus öyküsü varken, 219 (\%72.8)'unda abortus öyküsü yoktu. HBsAg negatif gebelerin 70 (\%23.3)'inde abortus öyküsü mevcutken, 231 (\%76.7)'inde abortus öyküsü yoktu. HBsAg pozitif ve negatif gebeler arasında abortus öyküsü açısından istatiksel olarak anlamlı fark yoktu ( $\mathrm{p}>0.05)$. HBsAg pozitif gebelerin 5 (\%1.7)'inde plesanta dekolman öyküsü, 1(\%0.3)'inde plesanta previa öyküsü mevcuttu. Plesanta dekolmanı ve plesanta previa öyküsü açısından HBsAg pozitif ve negatif gebeler karşılaştırıldığında istatistiksel olarak anlamlı fark tespit etmedik ( $>00.05)$. HBsAg pozitif gebelerin 2 (\%0.7)'inde, HBsAg negatif gebelerin ise 6 (\%2)'inde preeklampsi öyküsü mevcuttu. HBsAg pozitif gebelerin 4 (\%1.3)'ünde GDM öyküsü mevcutken, HBsAg negatif gebelerde GDM öyküsü yoktu. Preeklampsi ve GDM açısından HBsAg pozitif ve negatif gebeler arasında istatistiksel olarak anlamllık yoktu ( $\mathrm{p}>0.05)$. HBsAg pozitif ve negatif gebelere ait özellikler tablo 1'de verildi (Tablo1).

\begin{tabular}{|c|c|c|c|c|}
\hline & & $\begin{array}{l}\text { HBsAg } \\
\text { Pozitif } \\
(\mathrm{N} / \%)\end{array}$ & $\begin{array}{c}\text { HBsAg } \\
\text { Negatif } \\
(\mathrm{N} / \%)\end{array}$ & $\mathrm{p}$ \\
\hline \multirow{2}{*}{$\begin{array}{l}\text { Doğum } \\
\text { Şekli }\end{array}$} & $\begin{array}{l}\text { Normal Vaginal } \\
\text { Doğum }\end{array}$ & $189(\% 62,8)$ & $195(\% 64,8)$ & \multirow[t]{2}{*}{$>0,05$} \\
\hline & Sezaryen & $112(\% 37,2)$ & $106(\% 35,2)$ & \\
\hline \multirow{2}{*}{$\begin{array}{l}\text { Abortus } \\
\text { öyküsü }\end{array}$} & Evet & $82(\% 27,2)$ & $70(\% 23,3)$ & \multirow{2}{*}{$>0,05$} \\
\hline & Hayır & $219(\% 72,8)$ & $231(\% 76,7)$ & \\
\hline \multirow{2}{*}{$\begin{array}{l}\text { Plesanta } \\
\text { Dekolmanı }\end{array}$} & Evet & $5(\% 1,7)$ & $1(\% 0,3)$ & \multirow{2}{*}{$>0,05$} \\
\hline & Hayır & $296(\% 98,3)$ & $300(\% 99,7)$ & \\
\hline \multirow{2}{*}{$\begin{array}{l}\text { Plesanta } \\
\text { Previa }\end{array}$} & Evet & $1(\% 0,3)$ & 0 & \multirow{2}{*}{$>0,05$} \\
\hline & Hayır & $300(\% 99,7)$ & $301(\% 100)$ & \\
\hline \multirow{2}{*}{ Preeklampsi } & Evet & $2(\% 0,7)$ & $6(\% 2)$ & \multirow{2}{*}{$>0,05$} \\
\hline & Hayır & $299(\% 99,3)$ & 295 (\%98) & \\
\hline \multirow{2}{*}{$\begin{array}{l}\text { Gestasyonel } \\
\text { Diabetus } \\
\text { Mellitus }\end{array}$} & Evet & $4(\% 1,3)$ & 0 & \multirow{2}{*}{$>0,05$} \\
\hline & Hayır & $297(\% 98,7)$ & $301(\% 100)$ & \\
\hline
\end{tabular}

HBsAg pozitif gebelerin bebeklerinin doğum kiloları 2900-3392 gr arasinda olup, ortalama 3110 gr'di. HBsAg negatif anne bebeklerinin doğum kiloları 2757-3435gr (ort.3085gr) arasında idi. HBsAg pozitif ve negatif anne bebeklerinin doğum kiloları açısından istatiksel olarak anlamlı fark yoktu $(\mathrm{p}>0.05)$. HBsAg pozitif anne bebeklerinin 6 (\%2)'nda ve HBsAg negatif anne bebeklerinin de 6 (\%')'inda İUGR vardı. Fark istatiksel olarak anlamlı değildi ( $p>0.05$ ). HBsAg pozitif annelerin bebeklerinin 12 
(\%4)'inde, HBsAg negatif anne bebeklerinin 4 (\%1.3)'ünde fetal distres mevcuttu. HBsAg pozitif ve negatif annelerin bebekleri fetal distres açısından karşılaştırıldıklarında istatiksel olarak anlamlı fark vardı $(\mathrm{p}<0.05)$. Bebeklere ait fetal özellikler tablo2'de verildi (Tablo2).

\begin{tabular}{|c|c|c|c|c|}
\hline \multicolumn{5}{|c|}{ Tablo2. Bebeklere Ait Fetal Özellikler } \\
\hline & & $\begin{array}{c}\text { HBsAg(+) Anne } \\
\text { Bebekleri } \\
\mathrm{N}(\%)\end{array}$ & $\begin{array}{c}\text { HBsAg(-)Anne } \\
\text { Bebekleri } \\
\mathrm{N}(\%)\end{array}$ & $\mathrm{p}$ \\
\hline \multirow{2}{*}{ Cinsiyet } & Erkek & $157(\% 52,2)$ & $152(\% 50,2)$ & \multirow{2}{*}{$>0,05$} \\
\hline & $\mathrm{K} 1 \mathrm{z}$ & $144(\% 47,8)$ & $149(\% 49,8)$ & \\
\hline $\begin{array}{l}\text { Doğum } \\
\text { Kilosu }\end{array}$ & Ort. & $\begin{array}{c}3110(2900- \\
3392)\end{array}$ & $\begin{array}{c}3085 \text { (2757- } \\
3435)\end{array}$ & $>0,05$ \\
\hline \multirow{2}{*}{ İUGG* } & Evet & $6(\% 2)$ & $6(\% 2)$ & \multirow{2}{*}{$>0,05$} \\
\hline & Hayır & $295(\% 98)$ & $295(\% 98)$ & \\
\hline \multirow{2}{*}{ Fetal Distres } & Evet & $12(\% 4)$ & $4(\% 1,3)$ & \multirow{2}{*}{0,036} \\
\hline & & $289(\% 96)$ & $297(\% 98,7)$ & \\
\hline
\end{tabular}

\section{Tartışma}

Gebelikte HBV enfeksiyonun seyri ve gebelik üzerine etkisi üzerine yapılmış çalışmalar kesinlik kazanmamıştır. Kimi çalışmalar maternal fetal riskleri artırdığı yönündeyken bazı çalışmalar ise herhangi bir risk artışı olmadığını belirtmektedir.

HBsAg taşıyıcılığının gebeliğe etkisi üzerine yapılan bir vaka-kontrol çalışmasında HBsAg taşıyıcısı olan gebelerde erken doğum tehdidi, GDM ve antepartum hemorajide artmış risk tespit edilmiştir. Bu durumun gebelerde HBV enfeksiyonundaki kronik inflamatuvar sürece bağlı olabileceği belirtilmiştir ${ }^{5}$. Wong ve arkadaşlarının yaptığı bir çalışmada ise HBV enfeksiyonunun gebelik üzerine ek bir risk getirmediği bildirilmektedir ${ }^{8}$. Retrospektif yapılmış bir çalışmada HBsAg pozitif gebe kadınlarda GDM, postpartum hemoraji, intrahepatik kolestaz ve sezaryen oranları daha yüksek olduğu; preeklampsi ve plesanta previa riskinde istatiksel anlam olmadığı bildirilmiştir9 ${ }^{9}$ Çalışmamızda kronik HBV enfeksiyonunun maternal riskleri artırmadığını tespit ettik
Hepatit B virüsü ile enfekte gebelerde artmış düzeyde olan IL-2, 6, 10, MİF ve TNF-alfa gibi proinflamatuvar sitokinlerin, fetal riskleri artırmasının yanında gebelerde erken doğum riskine neden olabileceği belirtilmektedir ${ }^{5}$. Çalışmamızda abortus ile sonuçlanan gebe sayısı $82(\% 27,2)$ idi. Diğer taraftan sağlıklı kontrollerde bu sayı 70 (\%23,3)'di. Yapılan bir çalışmada kronik hepatit B'li annelerde abortus oranları sağlıklı gebelerle kıyaslanabilir olduğunu göstermiştir. ${ }^{10}$ Hepatit B'li annelerin bebeklerinin doğum kiloları ortalama 3110 (2900-3392)g ve IUGG olan bebek sayısı 6 (\%2) idi. Çalışmamızın sonuçlarından da anlaşıldı$\breve{g} 1$ üzere kronik HBV enfeksiyonun varlığı hasta ve sağlıklı kontroller arasında komplikasyon gelişimi açısından bir farklılık oluşturmamaktadır.

Gebelik döneminde yüksek viral yük (107 IU/ml) ve HBeAg pozitifliği özellikle normal vajinal yolla doğan yenidoğanda enfeksiyona neden olabileceği belirtilmektedir ${ }^{11}$. Çalışmamızda yalnızca 53 annenin $\mathrm{HBeAg} / \mathrm{HBeAb}$ durumuna ve yalnızca beş annenin de viral yük sonuçlarına ulaşabildik. İki annenin HBeAg pozitif, beş annenin viral yükü ise $\geq 2000 \mathrm{IU} / \mathrm{ml}$ idi. HBeAg pozitif ve viral yükü 19874497 IU/ml olan anne bebeğinde yaptığımız takipte, aşı ve HBIG uygulanmasına rağmen antikor yanıtının gelişmediğini kaydettik. Sonuçlarına ulaşabildiğimiz hasta sayısının az olması nedeniyle sonuçlar istatistiksel değerlendirmeye alınmadı. Ülkemiz gerçeğinde farkettiğimiz durum ise kronik HBV enfeksiyonu olan gebelerin ilgili uzmanlarla konsültasyonlarının ve takiplerinin yapılmamış olmasıdır. Bu bağlamda hastalara, hastalıkları hakkında bilgilendirmeler yapılmalı, takiplerinin daha düzenli olması ve enfeksiyon hastalıkları veya gastroenteroloji uzmanlarına yönlendirilmeleri açısından kadın doğum uzmanlarına eğitim verilmelidir.

Gebeliğin 3. trimestırında HBV DNA düzeyi >107 kopya/ $\mathrm{ml}$ olan gebelere perinatal bulaşı önlemek adına antiviral tedaviler önerilmektedir ${ }^{12,13}$. Çalışmamızdaki hastalar kronik hepatit B enfeksiyonu yönüyle hepsi eksik takipli yada takipsiz olduklarından hiçbirinde antiviral tedavi başlan- 
mamıştı. Gebelikte yüksek viral yükü olan hastalara uygun antiviral tedavi ile viral yük negatifleşmekte ve fetal geçiş riski de azalmaktadır. Ülkemizde yapılan bir çalışmada gebelik döneminde antiviral tedavi başlanan hastaların 6.ayında viral yükün negatifleştiği görülmüştür ${ }^{14}$.

HBsAg pozitif gebelerdeki sezaryen öykülerine bakıldığında, hepatit B'si olmayan hastalarla neredeyse aynı oranlarda olduğunu gördük. Bunu hepatit B enfeksiyonun gebelikteki riskleri artırmadığ 1 ve doktorun sezaryen veya normal doğum kararını etkilemediği sonucunu çıkarabiliriz. Sezaryen veya normal vajinal yol ile doğum yapan HBsAg pozitif gebelerin iletişim bilgilerinin eksik olması nedeniyle ileriye dönük perinatal geçiş riskini de değerlendiremedik. Viral yükü yüksek ve HBeAg pozitifliği olan tek olgumuzun doğum eylemi normal vajinal yol ile gerçekleşmişti. Yapılan bazı çalışmalar elektif sezaryenla doğumun vajinal doğuma göre HBV enfeksiyonu geçiş oranını azalttığını ${ }^{15,16}$ belirtirken bazı çalışmalar ise birbiriyle çelişen sonuçlar sunmaktadır ${ }^{17,18}$.

Hepatit B virüs enfeksiyonu olan gebelerin bebeklerindeki fetal riskler, HBV enfeksiyonu olmayan gebelerin bebekleriyle benzer olduğu bildirilmektedir ${ }^{8}$. Farklı çalışmalarda gebelikte HBV enfeksiyonu erken doğum, düşük doğum ağırlığı gibi fetal riskleri artırdığı yönündeyken bazı çalışmalarda ise erken doğum, düşük doğum ağırlığı, prematürite ve konjenital anomali gibi fetal risklerde HBV enfeksiyonu olmayan gebelerin bebeklerine göre bir farklılık olmadığı bildirilmektedir ${ }^{5,6,7}$. Çalışmamızda HBV ile enfekte annelerin bebeklerinde fetal distres $(0,036)$ haricinde fetal risk parametrelerinde artış tespit etmedik.

\section{Sonuç}

Tüm gebelerin hepatit B yönüyle taranması zorunlu hale getirilmelidir. Maternal HBV enfeksiyonu varlığının maternal riskleri artırmadığı sonucunu çıkarabilmemiz için çok daha fazla sayıda vakanın bir arada olduğu çalışmalara ihtiyaç vardır. Ayrıca hem fetal sağlığı korumak hem de HBV enfeksiyonuna bağlı maternal komplikasyonlardan korunmak amacıyla gebelerin gebelikleri sırasında ilgili uzmanlık alanlarınca yakın takibi gerekmektedir. 
Journal of BSHR 2019;3(3):208-212

ALAY, ȘAHINER, PARLAK. Maternal Kronik Hepatit B Virüs Enfeksiyonu

\section{Kaynaklar}

1. McMahon BJ (2005) Epidemiology and natural history of hepatitis B. Semin Liver Dis 25 Suppl 1: 3-8.

2. Sarin SK, Kumar M (2010) Epidemiology, Screening, and Natural History of Chronic Hepatitis B Infection. In: Shetty $\mathrm{K}, W u$ GY, editors. Chronic Viral Hepatitis 2nd ed. Lippincott, Williams, and Wilkins (Philadelphia): Humana Press. pp. 185-241.

3. Jonas MM. Hepatitis B and pregnancy: an underestimated issue. Liver International 2009; 29 Suppl 1: 133-139.

4. Han GR, Xu CL, Zhao W, Yang YF. Management of chronic hepatitis B in pregnancy. World J Gastroenterol. 2012; 18(33): 4517-21.

5. Tse KY, Ho LF, Lao T. The impact of maternal HBsAg carrier status on pregnancy outcomes: a case-control study. J Hepatol. 2005;43:771-5.

6. Reddick KL, Jhaveri R, Gandhi M, James AH, Swamy GK. Pregnancy outcomes associated with viral hepatitis. J Viral Hepat. 2011;18:e394-8.

7. Safir A, Levy A, Sikuler E, Sheiner E. Maternal hepatitis B virus or hepatitis C virus carrier status as an independent risk factor for adverse perinatal outcome. Liver Int. 2010;30:76570 .

8. Wong $S$, Chan $L Y, Y u$ V, Ho L. Hepatitis B carrier and perinatal outcome in singleton pregnancy. Am J Perinatol 1999; 16: 485- 488 .

9. Tan J, Liu X, Mao X, Yu J, Chen M, Li Y, Sun X. HBsAg positivity during pregnancy and adverse maternal outcomes: a retrospective cohort analysis. J Viral Hepat. 2016 Oct;23(10):812-9.

10. Lapinski TW, Stepaniuk J, Tomasiewicz K, Lebenstejn D, Kulikowski M, Flisiak R. Effect of hepatitis $B$ virüs infection on the course of pregnancy and newborns' health status. Clinical and Experimantal Hepatology 2015;3:112-116.
11. Dwedi M, Misra SP, Misra V, et al. Seroprevalence of hepatitits B infection during pregnancy and risk of perinatal transmission. Indian J Gastroenterol 2011;30:66-71.

12. Zou H, Chen Y, Duan Z, Zhang H, Pan C. Virologic factors associated with failure to passive-active immunoprophylaxis in infants born to HBsAg positive mothers. J Viral Hepat. 2012;13(2):18-25

13. Han GR, Xu CL, Zhao W, Yang YF. Management of chronic hepatitis B in pregnancy. World J Gastroenterol. 2012; 18(33): 4517-21.

14. Yang J, Zeng XM, Men YL, Zhao LS. Elective caesarean section versus vaginal delivery for preventing mother to child transmission of hepatitis B virüs a systematic review. Virol J. 2008;5:100.

15. B.Baysal, S.Kaya, S. Aksoz, S. Comoğlu, M. Cabalak, E.Arslan, H.Colak, N.Akmirza, R. Tekin, P. Tantekin. Efficacy and Safety of Telbivudine in Chronic Hepatitis B Treatment Throughout the Entire Pregnancy Period. Viral Hepatitis Journal 2016;22(1):10-13.

16. Pan JO, Zou HB, Chen Y, Zhang X, Zhang H, Li J, Duan Z. Cesarean section reduces perinatal transmission of hepatitis $B$ virüs infection from hepatitis $B$ surface antigen-positive women to their infants. Clin Gastroenterol Hepatol. 2013;11:1349-55.

17. Liu CP, Zeng YL, Zhou M, Chen LL, Hu R, Wang L, Tang H. Factors assosiated with mother to child transmission of hepatitis $B$ virüs despite immunoprophylaxis. Intern Med. 2015;54:711-6.

18. Hu Y, Chen $Y$, Wen J, Xu C, Zhang $S, X u$ B, Zhou YH. Effect of elective cesarean section on the risk of mother to child transmission of hepatitis B virüs. BMC Pregnancy Childbird. 2013;13:119. 